\title{
Diagnóstico de manifestações patológicas de estruturas de concreto armado em edificação residencial - estudo de caso
}

\author{
C. A. Monteiro Penha Júnior \\ Contato engcarlosaecio@gmail.com \\ Centro Universitário Fanor Wyden, Fortaleza, Brasil
}

\begin{abstract}
RESUMO
Haja vista a importância dos cuidados com a degradação de uma edificação para evitar acidentes, este artigo visa analisar e diagnosticar as manifestações patológicas da estrutura de concreto armado do condomínio residencial através da vistoria, inspeção predial e do método GUT para avaliar a prioridade da correção com base no estado do elemento estrutural deteriorado deste estudo de caso. $\mathrm{O}$ objeto de estudo apresenta elementos estruturais com degradações graves que necessitam de reparos e correções o mais breve possível. Concluiu-se que a corrosão da armadura de aço é o principal mecanismo de deterioração do concreto sendo causada em alguns locais pela infiltração de água e gases agressivos provenientes de fumaça presente semanalmente.
\end{abstract}

Palavras chaves: Manifestações patológicas do concreto armado; Manutenção periódica; Inspeção predial; Método GUT.

\begin{abstract}
Bearing in mind the importance of taking care of the degradation of a building to avoid accidents, this article aims to analyze and diagnose the pathological manifestations of the reinforced concrete structure of the residential condominium through inspection, building inspection and the GUT method to assess the priority correction based on the state of the deteriorated structural element in this case study. The object of study presents structural elements with serious degradations that need repairs and corrections as soon as possible. It was concluded that the corrosion of the steel reinforcement is the main mechanism of deterioration of the concrete being caused in some places by the infiltration of water and aggressive smoke gases present weekly.
\end{abstract}

Keywords: Pathological manifestations of reinforced concrete; Periodic maintenance; Building inspection; GUT method.

\section{INTRODUÇÃO}

Na construção civil, uma edificação deve ser segura, durável e confortável para a sua devida função residencial, comercial ou institucional. De acordo com a ABNT NBR 15575-1 (2013), a 
durabilidade é a capacidade da edificação ou de suas partes de desempenhar suas finalidades que lhe foram atribuídas na concepção dos projetos durante a sua vida útil estabelecida, levando em consideração o uso e a manutenção da construção. O período de tempo em que uma edificação começou a ser usada ou operada até o momento em que o seu desempenho se torna inviável para atender as diretrizes de projeto é chamado de vida útil. Cada sistema, como a estrutura de concreto armado, que compõe o edifício tem a sua vida útil de projeto mínima estabelecida pelas normas brasileiras (ABNT NBR 15575-1, 2013).

A patologia das edificações estuda as deteriorações, os mecanismos e as causas das degradações do edifício. Watt (2007, apud AEEBC, 1994) relata que há três áreas distintas, embora estejam interrelacionadas, da definição de patologia da construção que devem ter atenção que são as áreas de preocupação da identificação, investigação e diagnóstico de defeitos existentes, do prognóstico dos defeitos diagnosticados e da elaboração e implementação programa de obras corretivas. Uma deterioração de grau pequeno pode tornar-se um problema mais grave com a ação dos agentes degradantes quando não é analisada, solucionada e recuperada a partir do uso da manutenção e da engenharia diagnóstica.

A manutenção da edificação é o conjunto de atividades com diretrizes que visam a conservação ou a recuperação dos sistemas prediais que são necessárias para atender os critérios de desempenho respeitando ou prolongando a sua vida útil (SOUZA; RIPPER, 1998). A manutenção é composta pela manutenção preventiva que objetiva a conservação dos elementos que constituem o edifício dificultando ou impedindo que ocorra falha de desempenho a partir de um programa de atividades de controle e monitoramento e relatórios técnicos e pela manutenção corretiva que visa uma intervenção e correção imediata após a ocorrência da degradação.

Os empreendimentos antigos com idade superior a 30 anos tendem a possuir muitas degradações em seus sistemas prediais, pois apesar da sua concepção e execução da construção terem respeitados as normas regulamentadoras e serem realizados com qualidade obtendo um desempenho dentro das diretrizes para ter durabilidade e respeitar a vida útil de projeto, a falta de manutenção, o mau uso da edificação por parte dos usuários e o tempo ocasionam manifestações patológicas que quando agravados podem inviabilizar a utilização da edificação e a sua recuperação terá um custo mais elevado. Geralmente, os edifícios antigos que apresentam os casos mais sérios são os de padrões populares devido, principalmente, à dificuldade financeira.

O trabalho tem como objetivo analisar, inspencionar e diagnosticar as manifestações patológicas da estrutura de concreto armado de um condomínio residencial localizado em Fortaleza.

\section{PROCEDIMENTO}

\subsection{Objeto do estudo de caso}

O objeto definido para este estudo de caso é um condomínio residencial composto por blocos de quatro pavimentos, sem subsolos, com idade de 37 anos, até a data de realização do estudo, construído pelo sistema estrutural de concreto armado de acordo com as normas regularizadoras vigentes do ano de 1983, porém o seu telhado é formado por terças e telhas de outros materiais construtivos. A sua estrutura é formada por lajes que são apoiadas nas vigas, estas são apoiadas nos pilares e estes na fundação. Para ter um nome referencial dos blocos do condomínio para fins privativo, ético e metodológico, adotou-se uma numeração fictícia de B1 a B6 para nomeá-los. Esses blocos são despostos em pares no terreno sendo B1 e B2, B3 e B4 e, por fim, B5 e B6 e foram construídos distante de cada par de blocos.

O local do condomínio está distante em média de 3,52 quilômetros do mar no bairro Praia do Futuro II e de 765 metros do rio Cocó e, sendo assim, está na zona de classe de agressividade ambiental II (CAA II) de acordo com o mapeamento da zona de agressividade realizado pelo PEC/UFC, 
Inovacon, Coopercon-CE, Sinduscon-CE e Cimento Apodi. A ABNT NBR 6118 (2014), explana que a CAA II tem uma agressividade moderada, uma classificação de ambiente urbana e um pequeno risco de deterioração da estrutura de concreto armado.

\subsection{Procedimento metodológico}

Realizou-se a busca por projetos e documentos da edificação e a vistoria visual utilizando meio fotográfico no local para o levantamento de subsídios. Cada pavimento da edificação foi vistoriado observando os problemas das suas áreas comuns que são os pilotis, as escadas e as partes estruturais externas dos apartamentos. Em seguida, a inspeção predial foi executada por meio de ensaio nãodestrutível que consistiu em inspeção visual coletando os dados com o uso do fissurômetro para medir as aberturas das fissuras, identificando a manifestação patológica com detalhes das suas características e o possível mecanismo de deterioração organizando os dados obtidos conforme a Tabela 1.

Tabela 1. Manifestações patológicas e mecanismo de deterioração.

\begin{tabular}{|c|c|c|}
\hline Problema & Manifestação patológica & Diagnóstico \\
\hline 01 & Imagem & \\
\hline $\mathrm{N}$ & Imagem & \\
\hline
\end{tabular}

Posteriormente, utilizou-se o método GUT em que consiste analisar a gravidade do problema considerando a intensidade dos danos, a urgência para que haja resolução do problema e a tendência da situação do problema considerando o seu desenvolvimento na ausência da correção. Meireles (2001) relata que no método GUT, os problemas serão avaliados com nota no valor de 1 a 5 para cada critério para fins de classificação de prioridade apresentada na Tabela 2.

Tabela 2. Critérios GUT e suas notas.

\begin{tabular}{|c|c|c|c|c|c|}
\hline \multirow{2}{*}{ Critério } & \multicolumn{5}{|c|}{ Nota } \\
\cline { 2 - 6 } & 1 & 2 & 3 & 4 & 5 \\
\hline Gravidade & Dano mínimo & Dano leve & $\begin{array}{c}\text { Dano } \\
\text { regular }\end{array}$ & $\begin{array}{c}\text { Grande } \\
\text { dano }\end{array}$ & Dano grave \\
\hline Urgência & $\begin{array}{c}\text { Longuíssimo } \\
\text { prazo }\end{array}$ & $\begin{array}{c}\text { Longo } \\
\text { prazo }\end{array}$ & Prazo médio & Curto prazo & Imediatamente \\
\hline Tendência & Desaparece & Reduz-se & Permanece & Aumenta & Piora muito \\
\hline
\end{tabular}

Fonte: Meireles (2001).

As notas obtidas em cada critério do método GUT para cada problema são multiplicadas para obter a resultante de GUT e, assim, identificar os problemas que deverão ser priorizados conforme a equação (1).

$$
\mathrm{W}=\mathrm{X} \times \mathrm{Y} \times \mathrm{Z}
$$




\section{Onde}

W é a resultante de GUT;

X é a nota da gravidade;

Y é a nota da urgência;

Z é a nota da tendência.

Os problemas foram classificados por ordem numérica decrescente a partir do maior valor da resultante de GUT. Meireles (2001) sugere a Tabela 3 apresentada abaixo para a aplicação do método GUT.

Tabela 3. Análise e resultado da manifestação patológica pelo método GUT com exemplificação.

\begin{tabular}{|c|c|c|c|c|c|}
\hline Problema & Gravidade & Urgência & Tendência & $\begin{array}{c}\text { Resultante de } \\
\text { GUT }\end{array}$ & $\begin{array}{c}\text { Prioridade } \\
\text { GUT }\end{array}$ \\
\hline 01 & 3 & 3 & 1 & 9 & $1^{\text {o }}$ \\
\hline $\mathrm{N}$ & $\mathrm{X}$ & $\mathrm{Y}$ & $\mathrm{Z}$ & $\mathrm{W}$ & $\mathrm{P}^{\mathbf{0}}$ \\
\hline
\end{tabular}

Fonte: Meireles (2001).

\section{RESULTADOS}

\subsection{Documentação}

O condomínio não possui os projetos de estrutura, arquitetura e instalações prediais da edificação guardados. Também não possui o manual de uso, operação e manutenção da edificação. Não há documentos técnicos das manutenções que possam ter sido realizadas durante todo o seu tempo de uso.

\subsection{Vistoria visual}

Observou-se que todos os blocos apresentam estado físico degastado e sujo devido à falta de manutenção e ao mau uso. Houveram reformas recentes que foram feitas na tentativa de corrigir os problemas, porém alguns já possuem degradações aparentes provavelmente causadas pelos procedimentos inadequados para a situação. Alguns moradores relataram que há ocorrência de fissuras em seus apartamentos, parte interna, que não foram vistoriadas e incluídas neste artigo por motivo de privacidade.

Durante as vistorias, observou-se a presença de fumaça gerada por queimadas desconhecidas na vizinhança do condomínio semanalmente e em horário específico sendo entre 16:00 as 17:30. Uma dessas queimadas foi tão intensa que o ambiente ficou com tonalidade cinza e pôde-se ver algumas cinzas flutuando no ar dos ambientes do condomínio. Segundo os moradores, essas queimadas ocorrem há anos.

\subsection{Inspeção visual}


Os resultados obtidos das manifestações patológicas incluindo as aberturas das fissuras localizadas em elementos estruturais durante a inspeção visual são apresentados com os possíveis mecanismos de deterioração na Tabela 4 a seguir.

Tabela 4. Problemas de manifestação patológica do estudo de caso.

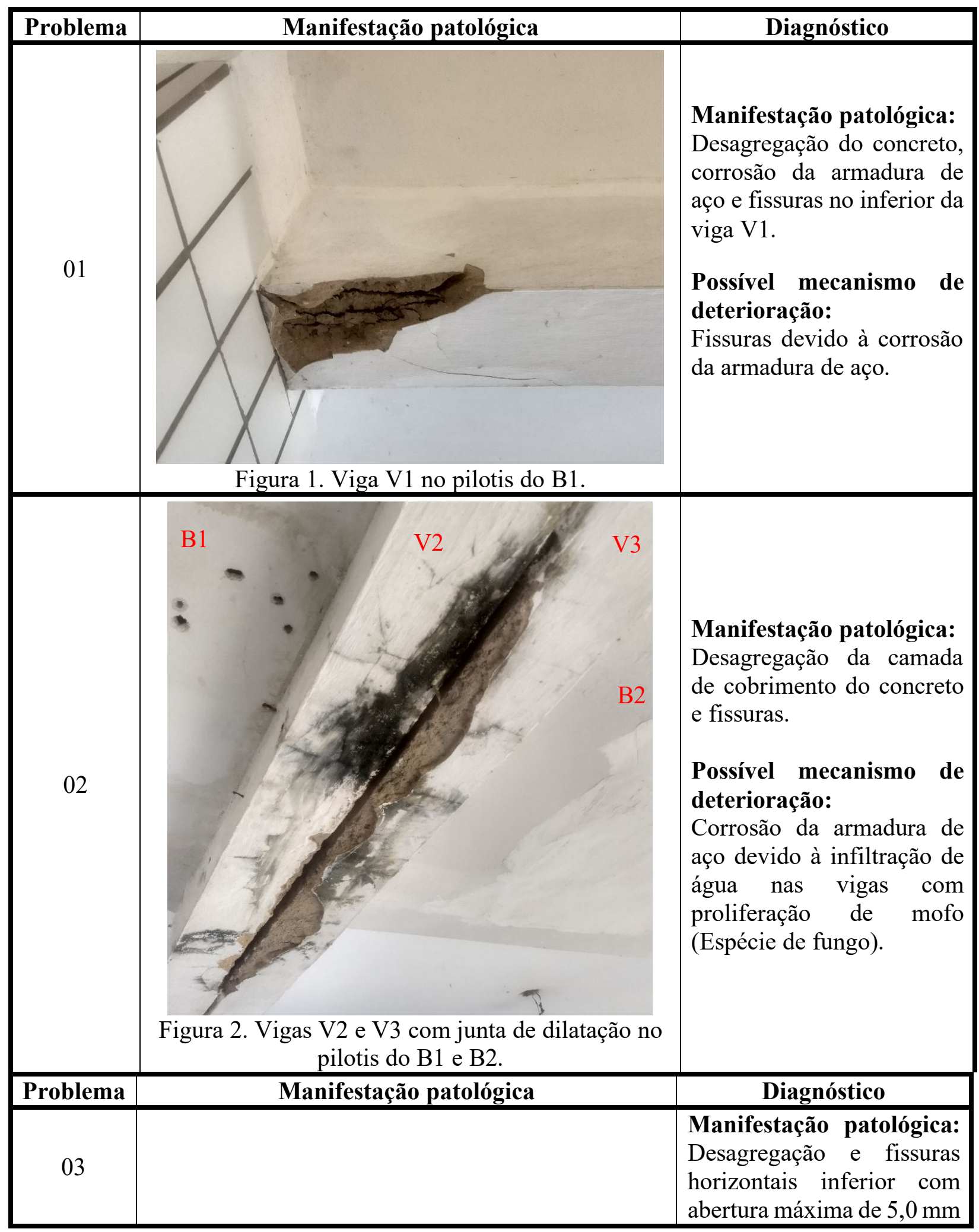




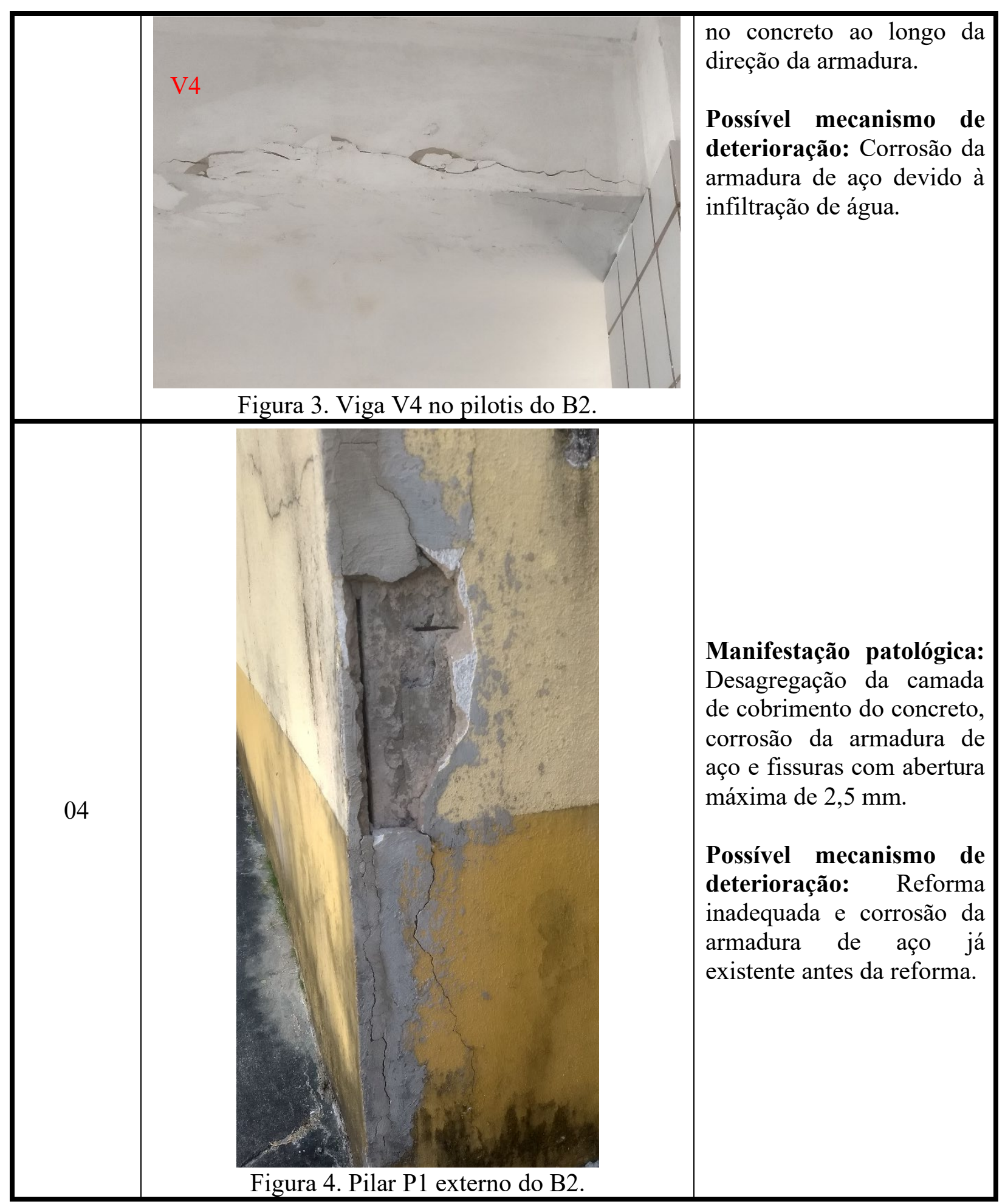

\section{Problema}




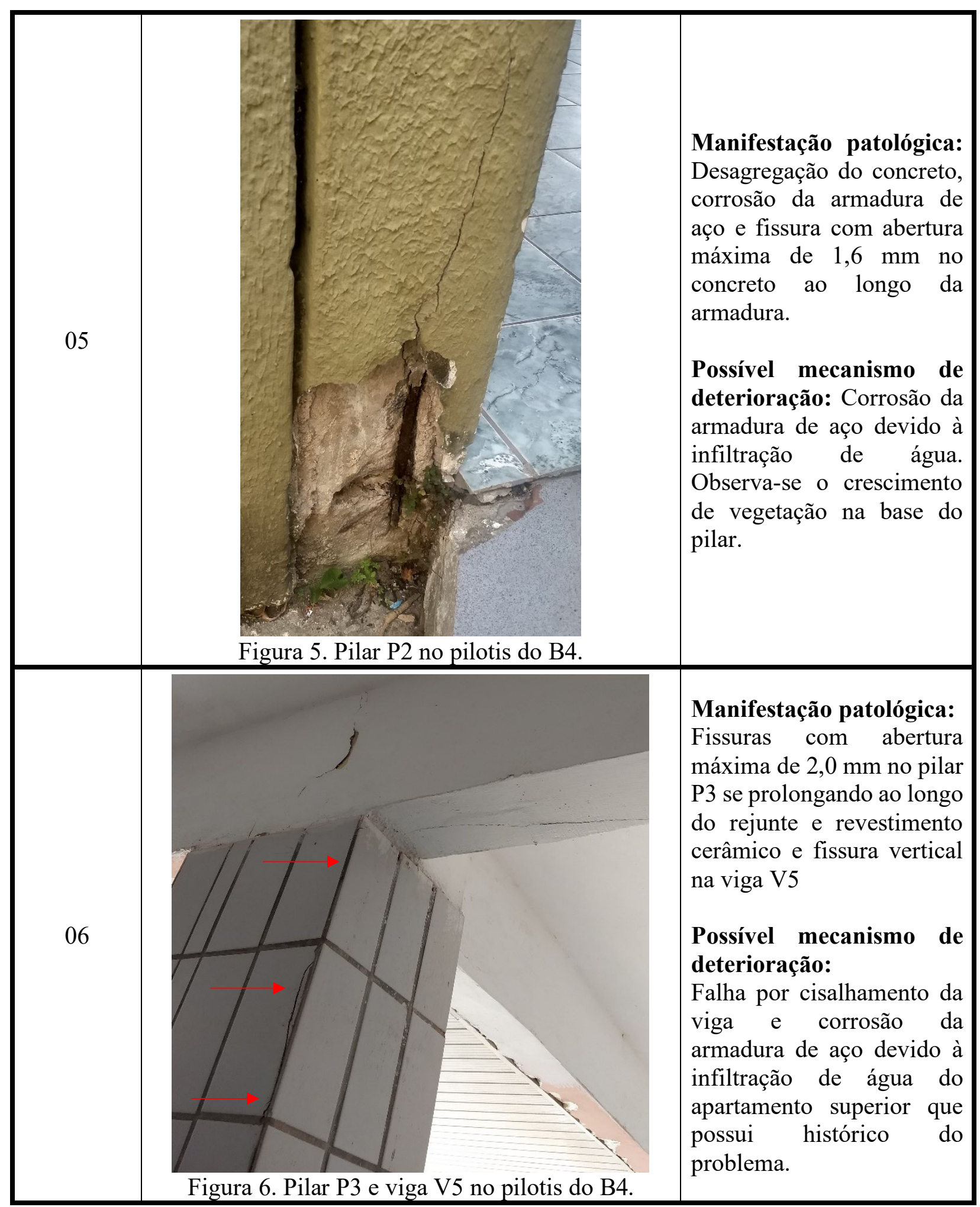

\section{Problema}

Manifestação patológica

Diagnóstico 


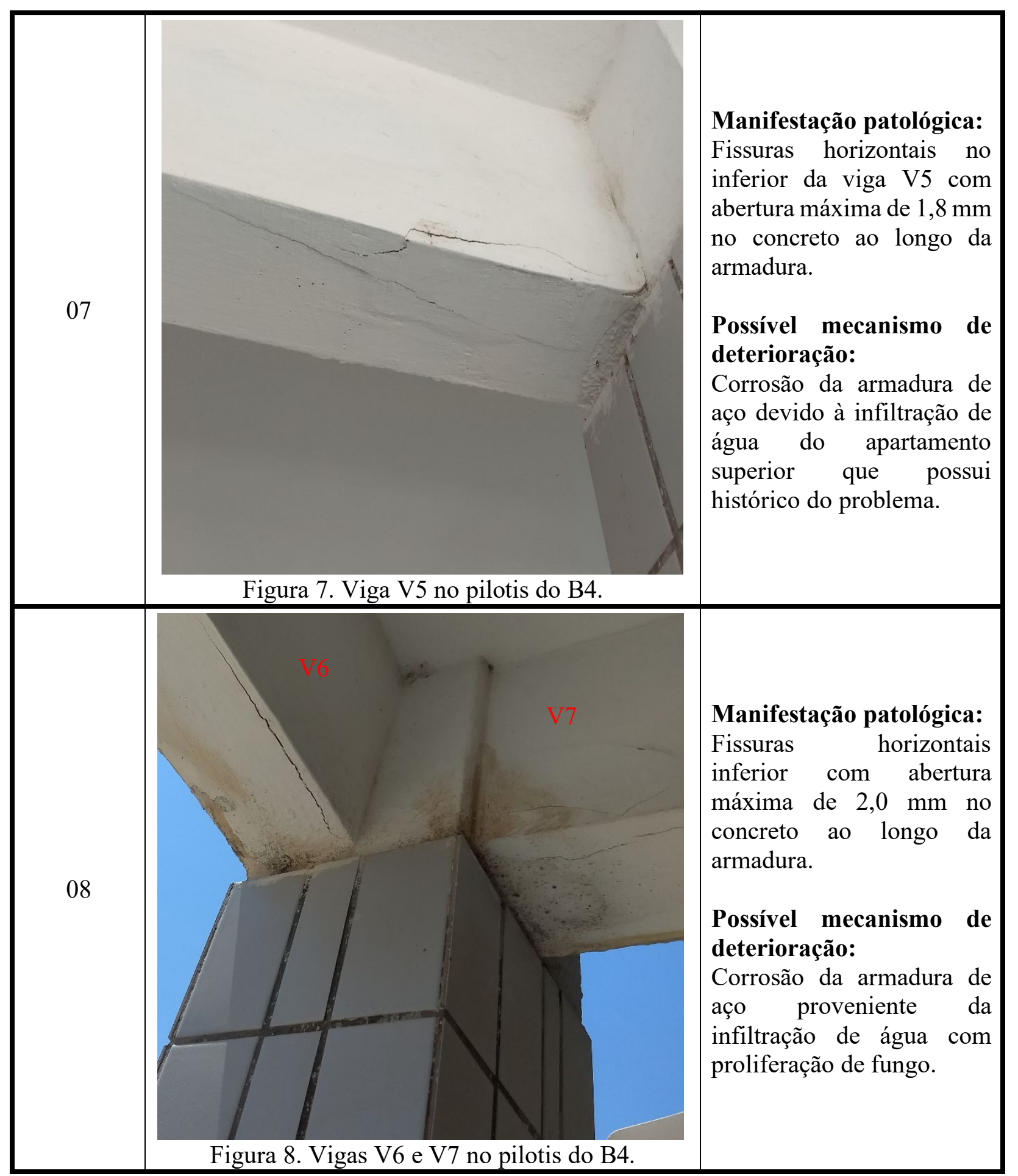




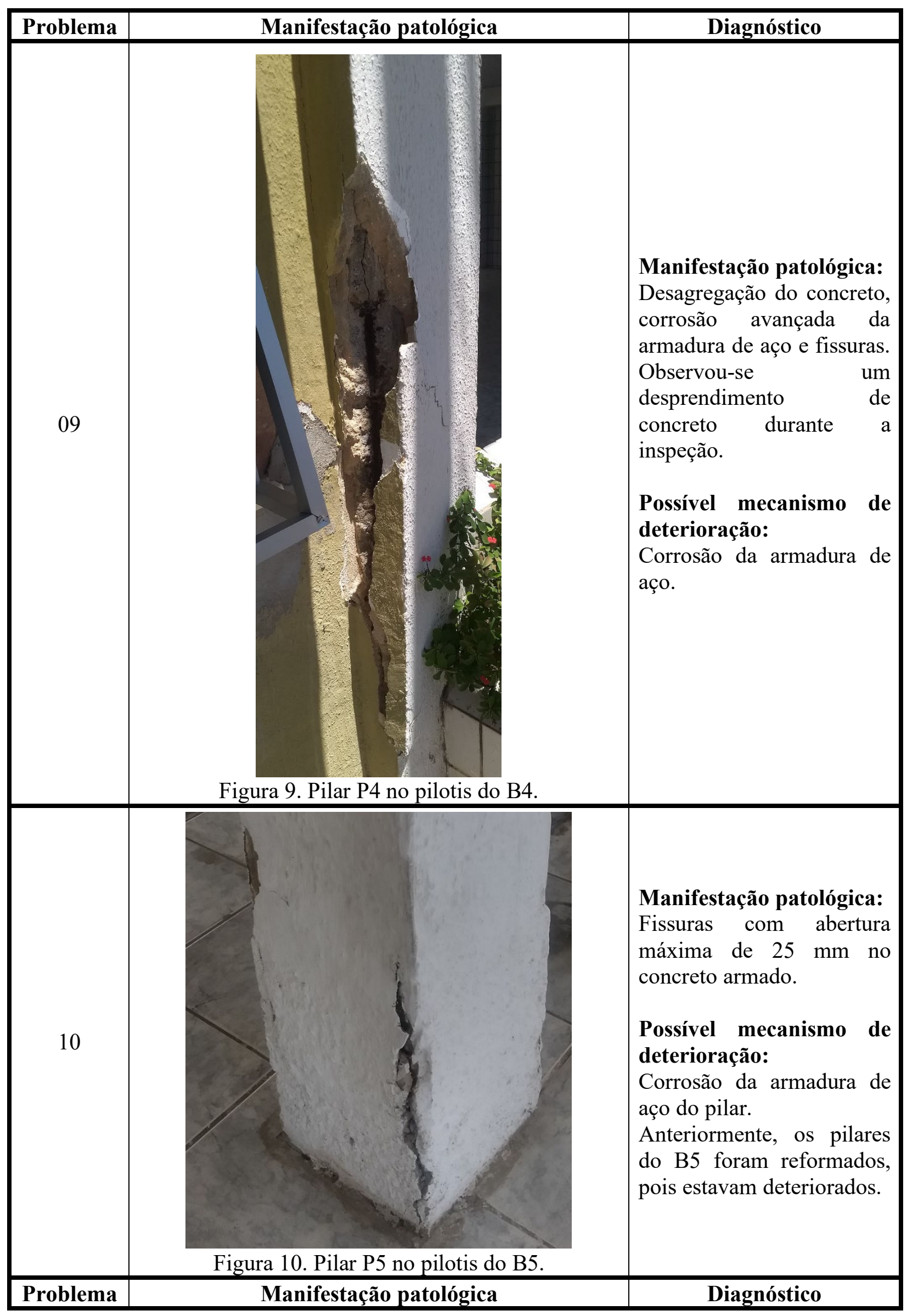




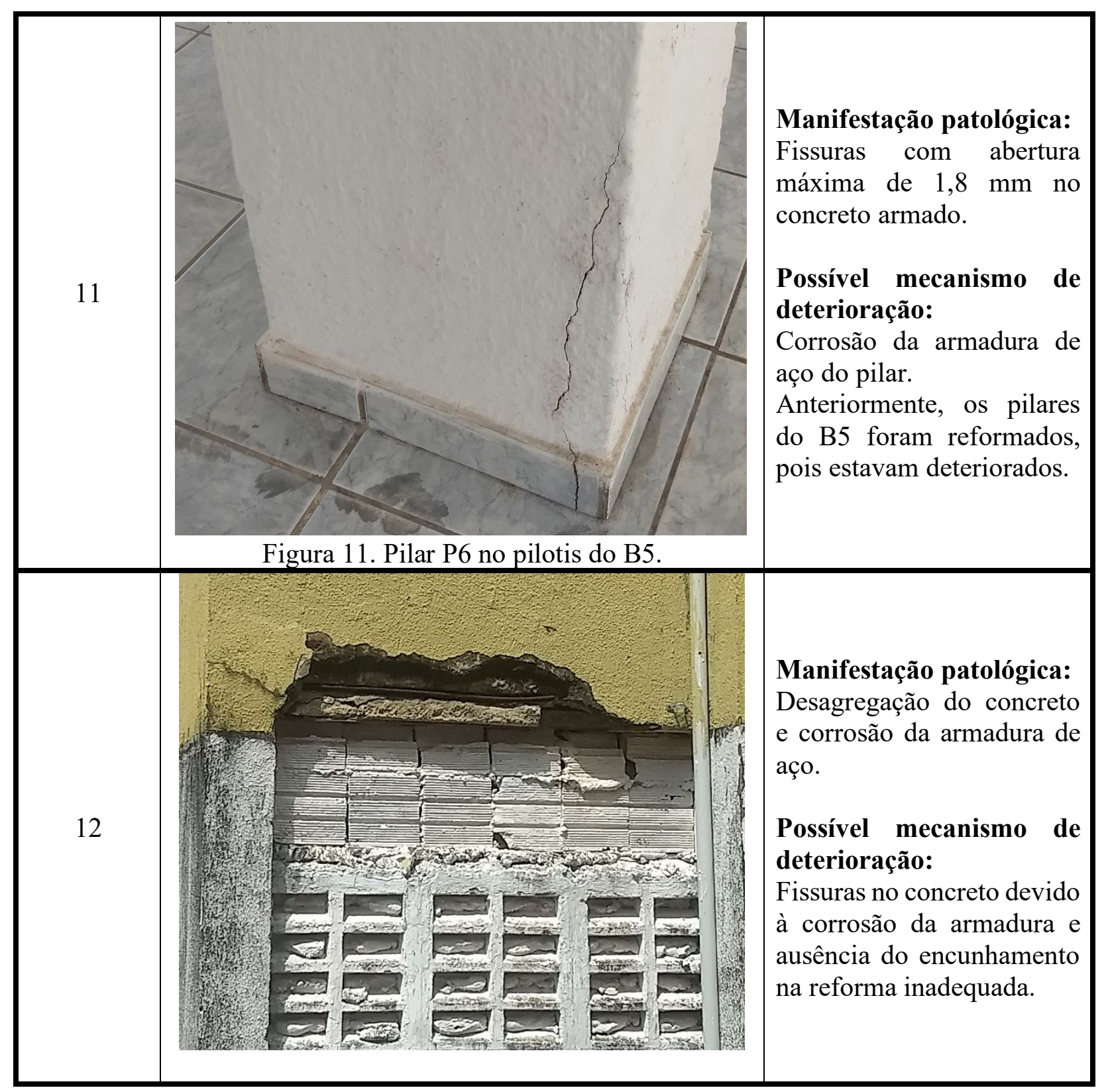




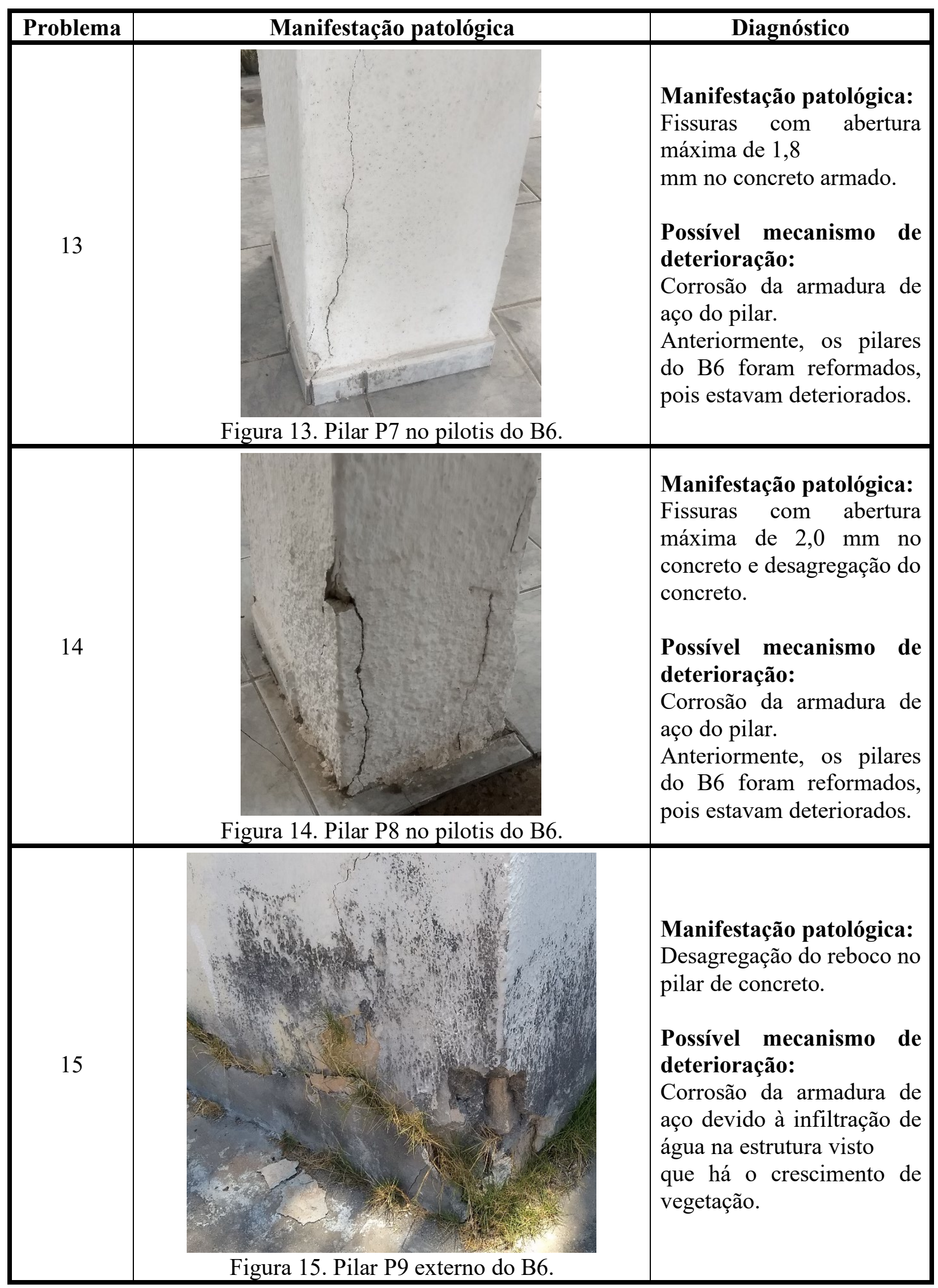




\subsection{Avaliação com o método GUT}

A partir da aplicação da metodologia de GUT nas manifestações patológicas dos dados da Tabela 4, pôde-se obter as resultantes e as prioridades de GUT para cada problema que são organizadas e apresentadas na Tabela 5 para corrigir cada problema estrutural considerando a ordem decrescente da resultante de GUT.

Tabela 5. Análise e resultado das manifestações patológicas pelo método GUT.

\begin{tabular}{|c|c|c|c|c|c|}
\hline Problema & Gravidade & Urgência & Tendência & $\begin{array}{c}\text { Resultante de } \\
\text { GUT }\end{array}$ & $\begin{array}{c}\text { Prioridade } \\
\text { GUT }\end{array}$ \\
\hline 01 & 5 & 5 & 5 & 125 & $1^{\text {o }}$ \\
\hline 02 & 5 & 5 & 5 & 125 & $1^{\text {o }}$ \\
\hline 03 & 4 & 5 & 4 & 80 & $2^{\text {o }}$ \\
\hline 04 & 5 & 5 & 5 & 125 & $1^{\text {o }}$ \\
\hline 05 & 5 & 5 & 5 & 125 & $1^{\text {o }}$ \\
\hline 06 & 5 & 5 & 5 & 125 & $1^{\text {o }}$ \\
\hline 07 & 4 & 4 & 4 & 64 & $3^{\text {o }}$ \\
\hline 08 & 5 & 5 & 5 & 125 & $1^{\text {o }}$ \\
\hline 09 & 5 & 5 & 5 & 125 & $3^{\text {o }}$ \\
\hline 10 & 4 & 4 & 4 & 64 & $3^{\text {o }}$ \\
\hline 11 & 4 & 4 & 4 & 64 & $1^{\text {o }}$ \\
\hline 12 & 5 & 5 & 5 & 125 & $3^{\text {o }}$ \\
\hline 13 & 4 & 4 & 4 & 64 & $3^{\text {o }}$ \\
\hline 14 & 4 & 4 & 4 & 64 & $3^{\text {o }}$ \\
\hline 15 & 4 & 4 & 4 & 64 & \\
\hline
\end{tabular}

\section{CONCLUSÕES}

Observou-se que os diagnósticos apresentaram um possível mecanismo de deterioração mais frequente que foi a corrosão da armadura de aço do concreto armado nos problemas identificados e principalmente no pilotis. Pode-se afirmar que a ação conjunta da fumaça de queimadas semanalmente incidindo no condomínio durante anos, da infiltração de água dos vazamentos da instalação hidráulica, da chuva e do aguamento de plantas para um dos blocos na estrutura e a ocorrência de reformas sem obedecer as diretrizes das normas técnicas contribuíram para o processo da corrosão da armadura de aço provavelmente através do fenômeno da carbonatação ou da ação de cloretos que causam a despassivação do aço deixando-o desprotegido aos agentes agressivos.

A partir das inspeções e da utilização do método GUT, pôde-se avaliar e classificar os riscos dos problemas patológicos identificados e concluiu-se que os blocos B4 por possuir ocorrências de infiltração de água com proliferação de fungo, de concreto se desagregando, armadura exposta e corroída em dois pilares com um terceiro pilar que foi, recentemente, reformado escondendo a corrosão do aço e vigas fissuradas, B1 por possuir ocorrência de infiltração de água com proliferação de fungo e de concreto se desagregando e armadura corroída em suas vigas, e B2 por possuir ocorrência de infiltração de água com proliferação de fungo, de fissuras em suas vigas e pilar com armadura exposta e corroída são os blocos que estão com a estrutura mais debilitada necessitando urgentemente de correção devendo ser escorados o mais breve possível. Os blocos 
B5 e B6 possuem quase todos os pilares no pilotis fissurados apesar de terem sido reformados a pouco tempo. O bloco B3 foi o que apresentou menos danos visuais à sua estrutura.

Neste artigo, a importância da existência e da utilização do manual de uso, operação e manutenção da edificação é evidente e comprovada visto que a sua ausência resultou na falta da manutenção preventiva e corretiva e em reformas inadequadas que, em conjunto com os agentes agressores do ambiente, ocasionaram danos que comprometeram o desempenho, durabilidade e a vida útil da estrutura do condomínio.

\section{REFERÊNCIAS}

ASSOCIAÇÃO BRASILEIRA DE NORMAS TÉCNICAS. NBR 15575-1: Edificações habitacionais - Desempenho Parte 1: Requisitos gerais. Rio de Janeiro, 2013.

INOVACON (Ceará), COOPERCON (Ceará), SINDUSCON (Ceará), Cimento Apodi, Programa de Pós-Graduação em Engenharia Civil: Estruturas e Construção Civil da Universidade Federal do Ceará. Cartilha estudo da agressividade do ar em Fortaleza/CE. Fortaleza, 2016.

MEIRELES, M. Ferramentas administrativas para identificar, observas e analisar problemas: organizações com foco no cliente. 1. ed. São Paulo: Art \& Ciência, 2001. 144 p.

PENHA JÚNIOR, Carlos Aécio Monteiro. Diagnóstico de manifestações patológicas de estruturas de concreto armado em edificação residencial - estudo de caso. In: congresso brasileiro de patologia das construções, 4. 2020. 4. ed. Anais [...]. Associação Brasileira de Patologias das Construções, 2020. 3731-3741 p.

SOUZA, V. C; RIPPER, T. Patologia, recuperação e reforço de estruturas de concreto. 1. ed. São Paulo: Pini, 1998. 255 p.

WATT, D. S. Building pathology: principles and practice. 2nd. Singapura: Blackwell Publishing Ltd, 2007. 320 p. 